\title{
General practitioner obstetrics in Bradford
}

\author{
F C Bryce, J K Clayton, R J Rand, I Beck, D I M Farquharson, S E Jones
}

\begin{abstract}
The standard of obstetric care by general practitioners in Bradford was assessed by reviewing the case records of all women who in 1988 were booked for delivery under their general practitioner but subsequently required transfer to consultant care. A total of 5885 women were delivered in Bradford during 1988. Of 1289 booked under their general practitioner, 637 required transfer to consultant care. In 259 cases transfer occurred during labour; only 37 of these women were visited by their general practitioner. Many of the problems that precipitated transfer were predictable and some were considered preventable: 263 of the women transferred were considered unsuitable for booking by general practitioners.
\end{abstract}

The perinatal mortality among women booked under their general practitioner was $10 \cdot 1 / 1000$ and the stillbirth rate $7 \cdot 8 / 1000$. These figures are high and suggest a need for tighter controls over the qualifications and experience of doctors participating in a fully integrated system of obstetric care.

\section{Introduction}

The role of general practitioners in obstetric care is the subject of continuing debate.' Antenatal care based in the community is increasing, but the role of general practitioners in intrapartum care is decreasing owing to small peripheral maternity units being closed, escalating legal costs, and intensive management techniques being adopted for women in labour. There are pressures to reverse this trend. General practitioners in Birmingham recently set up an independent body to support and promote obstetric care by general practitioners. Further encouragement comes from the government's plans to reform the NHS as set out in the white paper Working for Patients. No specific provisions have been made for obstetric care, and budgetary constraints may therefore become a powerful disincentive to referring women to a consultant unit.

In 1973 the delivery units at the two district general hospitals in Bradford became fully integrated and the last remaining separate general practitioner maternity unit was closed. Since then any general practitioner in Bradford has been able to admit an obstetric patient to a delivery unit bed and supervise her management independent of the hospital medical staff. Midwifery cover has been provided either by the woman's community midwife or, increasingly, by hospital based midwives. The only controls governing which women general practitioners should book and how labour should be managed are recommendations drawn up by the general practitioners, consultant obstetricians, and midwives on Bradford's planning team for expectant and nursing mothers (formerly the maternity liaison committee). These guidelines have been endorsed and distributed by the local medical committee. They include a list of indications for referral to consultant units known locally as the blue card. General practitioners are recommended to visit their patients on admission and ensure that the patient and midwifery staff can easily contact them throughout the labour. They should be informed when the second stage of labour starts so that they can, if possible, be present at the delivery. There is an agreed labour ward policy for inpatient management.

Bradford's system of integrated care has encouraged general practitioners to accept women for total obstetric care, but many of these patients have to be transferred to consultant care late in their pregnancy or labour. No attempt has been made to assess the importance of these trends. We studied the obstetric outcome among patients who were booked under their general practitioners but subsequently had to be transferred to the care of a consultant obstetrician.

\section{Methods and results}

We reviewed the case records of all patients transferred from the care of general practitioners to that of consultants during 1988. Information was sought regarding indications for booking, reasons for transfer, and obstetric outcome.

In 1988 there were 5885 births in Bradford. Total general practitioner obstetric care was initially booked for 1289 women. Only 652 remained under the care of their general practitioner for the whole of their pregnancy; 63 were delivered at home and 589 in hospital. The remaining 590 were transferred to consultant care. A further 47 women were seemingly booked for general practitioner care but subsequently transferred to consultant care late in their pregnancy without any change in indications.

Altogether 378 women were transferred to consultant care during the antenatal period (table I). The indications for transfer were considered to have been

TABLE I-Indications for transferring 378 women to consultant car antenatally

\begin{tabular}{lc}
\hline & $\begin{array}{c}\text { No of } \\
\text { women }\end{array}$ \\
\hline Postmaturity & 83 \\
Poor weight gain & 40 \\
Toxaemiat & 46 \\
Breech presentation & 35 \\
Fetus small for dates & 24 \\
High head after 36 wecks' gestation & 22 \\
Fetus large for dates & 19 \\
Reduced fetal movements & 16 \\
Anaemia (not responding to treatment & 14 \\
Non-specific abdominal pain & 9 \\
Unstable lie & 8 \\
Request for sterilisation & 6 \\
Uncertain dates & 5 \\
Patient's request & 5 \\
Oedema & 4 \\
Otherf & 37 \\
\hline
\end{tabular}

*Data not available for five women; 35 had more than one indication.

tHypertension induced by pregnancy in 29 women.

$\$ 24$ Indications, each occurring in at most three women. 
predictable in 115 women and preventable in 26. Preventable indications included untreated anaemia and uncertain dates in cases in which scans had been omitted. Transfer occurred after the 35th week of pregnancy in 253 cases and after term in 107. Table II shows the obstetric outcome among these women: there were three stillbirths and one early neonatal death. The 47 women who were seemingly booked for general practitioner delivery were given antenatal care by a general practitioner and not referred to a consultant until after the 35th week of pregnancy. Many of these late transfers were of women who breached the recommendations of the blue card (see table V).

A total of 259 women were transferred to consultant care as emergencies after admission to the delivery wards (table III). Further transfers were considered unnecessary either because the patients were not in established labour or because they had not been observed long enough for a diagnosis of failure to progress to be made. In 54 women complications arose that were considered preventable-for example, premature labour was misdiagnosed because steps had not been taken to verify dates.

Anaesthetists in Bradford do not offer an epidural service to women booked under general practitioners. Nevertheless, of the 42 women transferred in labour because of a request for epidural analgesia, 11 had made their intentions known early in pregnancy.

Only 37 patients were visited by their general practitioner despite developing problems considered

TABLE II-Outcome of pregnancy among 378 women transferred to consultant care antenatally

\begin{tabular}{lc}
\hline & $\begin{array}{c}\text { No of } \\
\text { women }\end{array}$ \\
\hline Normal delivery & 267 \\
Caesarean section & 52 \\
Forceps delivery & 24 \\
Breech delivery & 25 \\
Late miscarriage & 1 \\
Twins & 2 \\
Unknown & 3 \\
Transferred back to general practitioner & 4 \\
Birth weight $\leqslant 2500$ g & 23 \\
Baby sent to special care baby unit & 8 \\
Early neonatal death & 1 \\
Stillbirth & 3 \\
Postpartum haemorrhage & 4 \\
\hline
\end{tabular}

TABLE III - Indications for transferring 259 women in consultant care during labour

\begin{tabular}{lc}
\hline & $\begin{array}{c}\text { No of } \\
\text { women }\end{array}$ \\
\hline Fetal distress & 73 \\
Request for epidural analgesia $\dagger$ & 42 \\
Not in established labour & 25 \\
Failure to progress & 43 \\
Premature labour & 20 \\
Undiagnosed breech presentation & 11 \\
Antepartum haemorrhage & 8 \\
Third stage complication & 8 \\
Intrauterine death & 7 \\
Cord presentation & 2 \\
Other & 20 \\
\end{tabular}

*As shown by cardiotocographic changes in 31 cases and by meconium in 42.

tRequest made antenatally by 11 women.

TABLE IV-Outcome of pregnancy among 259 women transferred to consultant care during labour

\begin{tabular}{lc}
\hline & $\begin{array}{c}\text { No of } \\
\text { women }\end{array}$ \\
\hline Normal delivery & 191 \\
Caesarean section & 40 \\
Forceps delivery & 28 \\
Baby sent to special care baby unit & 20 \\
Early neonatal death & 2 \\
Stillbirth & 7 \\
\hline
\end{tabular}

TABLE V-Incidence of contraindications to care by a general practitioner among 1289 pregnant women booked by general practitioners in 1988

\begin{tabular}{|c|c|c|}
\hline & & 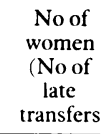 \\
\hline \multicolumn{3}{|l|}{ General: } \\
\hline Primigravida aged $\geqslant 30$ & & $13(2)$ \\
\hline Age $\leqslant 17$ & & 8 \\
\hline Height $\leqslant 152 \mathrm{~cm}$ & & $141(3)$ \\
\hline Height not recorded ${ }^{\star}$ & & 30 \\
\hline Essential hypertension $\geqslant 140 / 90 \mathrm{~mm} \mathrm{Hg}$ & & 5 \\
\hline Obesity (weight $\geqslant 100 \mathrm{~kg}$ ) & & 3 \\
\hline \multicolumn{3}{|l|}{ Previous obstetric history: } \\
\hline Pre-eclamptic toxaemia & & $23(3)$ \\
\hline Caesarean section & & $11(10)$ \\
\hline Mid-cavity forceps delivery & & $9(1)$ \\
\hline Third stage difficulties & & $13(1)$ \\
\hline Third degree tear ${ }^{\star}$ & & $4(1)$ \\
\hline Premature delivery at $\leqslant 37$ weeks & & $15(1)$ \\
\hline Intrauterine growth retardation (birth weight $\leqslant 2$ & g) & 15 \\
\hline Baby with cerebral palsy ${ }^{\star}$ & & 1 \\
\hline Baby with birth weight $\geqslant 4500 \mathrm{~g}^{\star}$ & & 5 \\
\hline Shoulder dystocia ${ }^{\star}$ & & 1 \\
\hline Hysterotomy or multiple terminations of pregna & & 2 \\
\hline Antepartum haemorrhage & & \\
\hline Antepartum metabolic disease & & 1 \\
\hline Inherited metabolic disease & & $1(1)$ \\
\hline Idiopathic thrombocytopenia $^{\star}$ (checked only at & king) & $2(1)$ \\
\hline Multiple breech deliveries* & & 1 \\
\hline Miscarriage at week $26^{\star}$ & & 1 \\
\hline Hydatidiform mole* & & 1 \\
\hline Hydramnios & & 1 \\
\hline \multicolumn{3}{|l|}{ Present obstetric history: } \\
\hline Unreliable dates (no ultrasound scan done) ${ }^{\star}$ & & 24 \\
\hline Fetus small for dates ${ }^{\star}$ & & 15 \\
\hline Pre-eclamptic toxaemia & & 8 \\
\hline Refractory anaemia & & 13 \\
\hline Antepartum haemorrhage ${ }^{\star}$ & & $1(1)$ \\
\hline Placenta praevia after 34 weeks ${ }^{\star}$ & & 1 \\
\hline High head at term ${ }^{\star}$ & & 8 \\
\hline Postmaturity $\geqslant 10$ days $^{\star}$ & & 5 \\
\hline Reduced fetal movements ${ }^{\star}$ & & 1 \\
\hline Recurrent glycosuria ${ }^{\star}$ & & 2 \\
\hline Threatened miscarriage & & 3 \\
\hline \multicolumn{3}{|l|}{${ }^{\star}$ Contraindications not listed on Bradford's blue card. } \\
\hline \multicolumn{3}{|c|}{$\begin{array}{l}\text { TABLE VI-Mortality statistics in Bradford for } 1988 \text {. Figures are } \\
\text { deaths per } 1000 \text { births }\end{array}$} \\
\hline 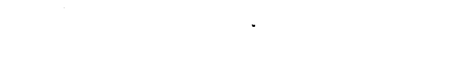 & $\begin{array}{l}\text { Stillbirth } \\
\text { rate }\end{array}$ & $\begin{array}{l}\text { Perinatal } \\
\text { mortality }\end{array}$ \\
\hline \multirow{2}{*}{$\begin{array}{l}\text { All deliveries } \\
\text { All women transferred to consultant care during } \\
\text { pregnancy }\end{array}$} & $9 \cdot 0$ & $13 \cdot 8$ \\
\hline & $15 \cdot 6$ & $20 \cdot 4$ \\
\hline \multirow{2}{*}{$\begin{array}{l}\text { Women transferred antenatally } \\
\text { All women booked by general practitioners } \\
\text { (including home deliveries) }\end{array}$} & $27 \cdot 0$ & 38.6 \\
\hline & $7 \cdot 8$ & $10 \cdot 1$ \\
\hline
\end{tabular}

serious enough to warrant transfer to consultant care. Eleven were seen by a representative of the doctors' deputising service and 145 by a midwife. In five cases this was because the general practitioner could not be contacted, and in four the problems arose so quickly that no contact was attempted. Table IV shows the obstetric outcome among women transferred in labour; there were seven stillbirths and two early neonatal deaths.

Of the 637 women booked for general practitioner care who required transfer either in the antenatal period or in labour, 263 were considered unsuitable for general practitioner care: 176 had at least one contraindication as listed on the blue card ( 49 had multiple contraindications), and 87 had other important risk factors that were not included on the blue card (table V).

Table VI shows the perinatal mortality and number of stillbirths in Bradford health district and among women booked for general practitioner care.

\section{Discussion}

Our findings raise several issues that give cause for concern. Perinatal mortality associated with general 
practitioner obstetrics is usually low because only low risk patients are booked. ${ }^{-8}$ Clearly this is not true in Bradford. The integrated delivery ward system seemingly creates a false sense of security, encouraging general practitioners to book unsuitable patients despite a well publicised list of specific contraindications (the blue card). The tendency of some general practitioners not to refer women to consultants until the last few weeks of pregnancy creates difficulties. It is often too late to organise specifically indicated investigations and to obtain necessary information about previous pregnancies.

Many women in Bradford who are told that the whole of their pregnancy will be supervised by their general practitioner find that he or she is not available when problems arise in labour. In 1988 four women required treatment so urgently that no attempt was made to contact the general practitioner. An important advantage of the integrated labour ward system is that general practitioners are not relied on in such cases. Nevertheless, although 255 women did not require emergency treatment, only 37 were visited by their general practitioner. Transferring women to a new set of medical attendants at this time of stress without any explanation from the family doctor they know and trust is clearly unsatisfactory. Furthermore, some of these transfers could have been prevented had the general practitioner visited. We endorse the local medical committee's recommendation that the doctors' deputising service is not used for intrapartum care.

The two hospitals in Bradford serve an urban population with a fairly high unemployment rate and associated socioeconomic deprivation. Nearly a third of pregnant women are Asians, who are often multiparous and of advanced maternal age and whose fetuses are particularly at risk of intrauterine growth retardation, premature delivery, congenital abnormalities, and inherited disorders such as thalassaemia. The rates of stillbirths and early neonatal death are therefore fairly high. Nevertheless, if general practitioners book only patients at low risk mortality statistics among women under general practitioner care should be comparable with those in other districts.

The John Radcliffe Hospital in Oxford serves a population of a similar size to that of Bradford. It has an integrated general practitioner unit that reported a crude perinatal mortality of 3/1000 births in 1987 . When congenital defects and extreme prematurity are excluded this corrects to zero ( $M$ Bull, personal communication). The crude perinatal mortality rate among women in Bradford booked under general practitioner care was $10 \cdot 1 / 1000$ in 1988 .

The Oxford unit is successful because only a few general practitioner obstetricians, who must hold a contract with the John Radcliffe Hospital, can admit patients to the delivery ward. Such a contract is recommended by the Royal College of Obstetricians and Gynaecologists and the Royal College of General Practitioners. ${ }^{9}$ It ensures that only general practitioners with sufficient past and current experience of intrapartum care book women and that they follow a strict code of practice regarding suitability for booking. General practitioners are encouraged to perform deliveries and compelled to attend at least five a year (the royal colleges' joint report suggests 30 in three years). General practitioners who do not meet the attendance requirement cannot have their contract renewed until they have attended a suitable refresher course. This amount of continuing experience is suggested to be necessary to fulfil a practitioner's legal responsibility - an observation of particular relevance at a time when litigation is becoming increasingly common.

No such controls on general practitioner bookings exist in Bradford. We do not know of any general practitioners who attended the delivery of a woman booked under their care during the study. Ninety five doctors transferred women to consultant care in 1988; all of the doctors were on the local obstetric list. The criteria for inclusion on an obstetric list were drawn up many years ago and are inappropriate to modern obstetric practice. Some general practitioners in Bradford, for example, earned their place simply by attending a few antenatal clinics and deliveries (criterion IV) and therefore would not comply with the requirements for intrapartum care of the two tier obstetric list proposed by the House of Commons Social Services .Committee (1980) and the General Medical Services Committee (1981). "' "The list was described as a policy for the 1980s and was welcomed by the royal colleges. It has not yet been implemented.

General practitioner obstetricians require a continuing programme of education. Regular meetings on perinatal mortality and morbidity are held in Bradford, but they are not compulsory and attendance is poor.

Perinatal mortality and particularly the stillbirth rate for Bradford Health District are fairly high (13.8 and $9 \cdot 0 / 1000$ respectively in 1988). Action has been taken to improve these statistics, and more is planned -for example, an extra consultant obstetrician has been appointed, permitting additional antenatal clinics and the presence of a full time consultant in the delivery wards. The ultrasonography department has been expanded and new monitoring equipment is available. There are also plans to centralise the hospital maternity services on one site. None of these changes are likely to have much influence on the high number of stillbirths and early neonatal deaths occurring among women booked under general practitioners

We have highlighted the potential dangers of a fully integrated system of obstetric care when there are no controls over the qualifications and experience of participating doctors or the standards of care they offer. The momentum for change as proposed by the social services committee and the General Medical Services Committee and endorsed by the royal colleges in their joint report seems to have been lost. We suggest the various recommendations should now be formally introduced.

1 Jewell D. General practitioner obstetrics. Br Med Y 1989;298:690-1.

2 Chamberlain (i. Obstetrics and the white paper. Br Med f 1989;298:1702-3.

3 Taylor (iW, Edgor W, Taylor BA, Neal D) $($. How safe is general practitioner obstetrics. Lancet 1986;ii: $1287-9$

+ Klein M, Llowd I, Redman C. Bull M. Turnbull AC. A comparison of low-risk pregnant women booked for delivery in two systems of care: shared-care consultant and integrated general practice unit. I. Obstetrical procedures Consultant and integrated general practice unit. I. Obstetrica
and neonatal outcome. Br F Obstel (ivnuecol 1983:90:118-22.

5 Klein M, Lloyd I, Redman C. Turnbull AC. A comparison of low-risk pregnant women booked for delivery in two systems of care: shared-care (consultant) and integrated general practice unit. II. Labour and delivery management and neonatal outcome. Brf ()bstet (ivnaecol 1983;90:123-8

6 Tew M. Place of hirth - perinatal mortality. 7 R Coll (ien Pract 1985;35:390)-4

7 Lowe SW, House W , Garrett T. Comparison of outcome of low-risk labour in an isolated general practice, maternity unit and a specialist maternity hospital. FR Coll (rén Pract 1987;37:484-7.

$8 \mathrm{Marsh}$ (GN, Channing DM. Audit of 26 vears of obstetrics in general practice. Br.Med f 1989:298: 1077-80

9 Joint Working Party of the Roval College of Obstetricians and Gynaccologists and the Roval College of General Practitioners. Report on training for obstetrics and gvnatcologu for general practitioners. London: Chameleon P'ress, 1981 .

10 Social Services Committee. Second report from the secial services committe 1980:perinatal and nematal mortalitv. London: HMSO, 1980. C(Cmnd 663 i-c.

11 General Medical Services Committee. (ieneral practitioner obstetrics-a policy for the '80s. Br.1led I 1981:282:1171-2.

Accepled 17 Hebruar log()

\section{Correction}

Portal vein thrombosis in myeloproliferative disease

A printer's error occurred in the diagram accompanying the case presented by Dr Helen Fidler ( 3 March, p 590). The vessel in the line diagram of the ultrasonogram should be labelled splenic vein and not splenic artery as published. 